\title{
Do Long-Tenure Workers Have Special Problems Following Job Displacement?
}

\author{
By: Christopher J. Ruhm*
}

Ruhm, Christopher J. "Do Long Tenure Workers Have Special Problems Following Job

Displacement" Economic Development Quarterly, Vol. 3, No. 4, November 1989, 320-

26.

Made available courtesy of SAGE PUBLICATIONS LTD: http://edq.sagepub.com/

***Note: Figures may be missing from this format of the document

\begin{abstract}
:
This article examines whether the adjustment problems that follow job displacement become more severe as preseparation tenure increases. Recent research using nation- ally representative samples generally finds that the independent effect of seniority is quite weak and is dwarfed by other factors such as ethnicity, gender, or regional economic conditions. There is some evidence that persons with very high seniority (over 20 years) suffer larger wage losses than do other workers and that they might also be expected to lose pension benefits under defined benefit plans. The findings provide no justification for the Bureau of Labor Statistics's narrow definition of displaced workers, which includes only persons with more than three years' seniority on preseparation employment.
\end{abstract}

\section{Article:}

The combination of back-to-back recessions in the early eighties, rapid advances in manufacturing technology, and increased competition from imported products has led to layoffs and plant closings in many industries. Sustained high rates of unemployment have slowed the reabsorption of these displaced workers, heightened concern over their problems, and resulted in a number of programs being designed to assist them. For example, the Trade Adjustment Assistance Act (TAA) of 1974 and Title III of the 1982 Job Training Partnership Act (JTPA) provide various forms of support for dislocated individuals including supplemental unemployment benefits, training, and reemployment assistance. These efforts are supplemented in some states by additional unemployment compensation, training assistance, or legislation mandating prior notification of plant closings. In addition, at the federal level, 1988 witnessed the passage of the omnibus trade bill, which authorized an almost threefold increase in federal retraining assistance for displaced workers, and of the first national legislation requiring mandatory advance notice of some involuntary job terminations.

Implicit in these programs is a special concern for long-service workers who are expected to have the strongest attachments to their firms, largest postlayoff earnings losses, and greatest difficulties obtaining reemployment. The belief that adjustment problems increase with seniority is so prevalent that the Bureau of Labor Statistics (BLS) excludes persons leaving jobs of less than three years' duration from their definition of displaced workers. Nonetheless, until recently,

\footnotetext{
*AUTHOR'S NOTE: An earlier version of this article was presented at the Allied Social Science Association meetings in Chicago, December 28-30, 1987.
} 
there has been surprisingly little examination of how the costs of economic dislocation vary with job tenure.

This article presents a brief summary of recent research examining postdisplacement adjustment patterns - with special attention paid to preseparation job duration. While this does not represent a complete review of the relevant literature and there are some differences across studies, three main findings emerge. First, the probability of suffering involuntary job loss declines dramatically with seniority. Second, once displaced, there is little evidence that joblessness or earnings reductions systematically increase with prior tenure. Third, the independent impact of seniority is dwarfed by factors such as ethnicity, regional economic conditions, and gender. Also, although the loss of fringe benefits may constitute a greater problem for high-seniority workers, existing research on this question is so limited as to provide little concrete information.

\section{DISPLACEMENT IN THE U.S. ECONOMY}

Virtually all workers now face the possibility of permanent layoffs at some point in their working lives. More than two million persons lost jobs annually between 1979 and 1986 as the result of plant closures or relocations, slack work, or a position or shift being abolished. ${ }^{1}$ Workers in manufacturing industries and blue-collar occupations account for a disproportionate share of the dislocated. ${ }^{2}$ Similarly, operators, fabricators, and laborers had a high relative incidence of displacement as did persons living in the heavily industrialized states of the Midwest and Middle Atlantic regions.

Despite the disproportionate share of jobs lost in durable goods industries, blue-collar occupations, and economically depressed localities, labor market dislocation occurs throughout the entire economy. For example, of the 5.1 million workers classified as displaced by Flaim and Sehgal between 1979 and 1983, one million were in the retail sales and service sectors, 1.9 million departed managerial, professional, technical, administrative, or sales jobs, and 260,000 terminated employment in the booming New England region. ${ }^{3}$ Given the widely dispersed incidence of displacement, the average seniority of employees in hard-hit sectors plays only a small role in determining whether low- or high-tenure workers are most vulnerable to economic dislocation. Much more important are the policies firms use in deciding which types of workers to release during cutbacks. In many cases, implicit or explicit policies dictate that layoffs will occur in inverse order of seniority. ${ }^{4}$ As a result, displacement probabilities decline steadily with seniority and the typical displaced worker is released from employment of fairly short duration. ${ }^{5}$

Given that long-tenure workers are much less likely to suffer economic dislocation than are individuals with lower seniority, special attention should be paid to their situation only if they experience much greater adjustment problems as a consequence of the displacement. The next three sections discuss whether this is the case.

\section{POSTDISPLACEMENT WAGE LOSSES}

Attachments to specific jobs are an important characteristic of the U.S. economy. More than half of the men between the ages of 40 and 55 will remain in their currently held job for 20 years or more, and 54\% will hold a job lasting more than 20 years during some part of their working lives. ${ }^{6}$ A number of economic theories hypothesize that these worker-firm attachments lead to 
upward-sloping earnings profiles and that because the seniority premiums are tied to particular jobs, long-service workers are unlikely to retain their higher wages following labor displacement. ${ }^{7}$ Early research on dislocated workers appeared to support these predictions. For example, case studies and analysis of TAA recipients suggested that displaced long-tenure workers were reemployed at lower wages than are their counterparts leaving shorter-lasting jobs. Given their higher expected initial earnings, this was taken to imply much larger wage losses.

Improved data on dislocated workers has led to a small explosion of empirical research studying postdisplacement adjustment patterns. This work substantially improves upon the earlier case studies and analyses that were limited to particular types of displaced individuals (such as TAA recipients) in that it uses nationally representative samples and attempts carefully to correct for a number of methodological problems that plague earlier research. ${ }^{8}$

The bulk of contemporary work suggests that high-tenure workers are less vulnerable, following displacement, than earlier theoretical and empirical studies predict. Abraham and Farber and Altonji and Shokotko argue that cross-sectional earning regressions overstate the returns to seniority by as much as $80 \%$. $^{9}$ This occurs because high-paying jobs last longer than lesser-paid employment and sorting therefore results in cross-sectional wage profiles that are steeper than true within-job earnings growth. ${ }^{10}$ Although these results are not conclusive, they suggest that the high wages of long-tenure workers may be transferable to postdisplacement employment. For example, if preseparation earnings are elevated because the individuals possess attributes that are valued across a wide variety of firms, there is no reason to expect them to suffer unusually large wage reductions following permanent layoffs.

The evidence of disproportionate wage reductions for long-tenure job leavers is quite weak and these are probably restricted to individuals with extremely long job durations (i.e., over 20 years). For example, Ruhm finds that while the relative wages of workers involuntarily terminating jobs of more than 10 years' duration decline by $7.3 \%$ (four years after displacement) compared to persons leaving jobs lasting less than three years, the corresponding reduction for nondisplaced individuals is an even larger $8.3 \% .^{11}$ This shows that failing to include a control group of nondislocated workers leads to an overestimate of the losses faced by displaced longtenure individuals because it does not account for the relative wage changes that would occur in the absence of the termination. Nonetheless, recent studies using samples that are restricted to displaced workers (and so suffer from this problem) show only a slight decline in relative wage growth as tenure increases. For example, Podgursky and Swaim find statistically insignificant tenure differentials for all displaced workers except blue-collar males, and even for this group, they estimate a fairly small loss — approximately $0.6 \%$ per additional year of tenure. ${ }^{12}$

It is also clear that a large portion of the returns to prior seniority are transferable to postdisplacement employment. For example, Kletzer uncovers a significant positive relationship between previous tenure and subsequent earnings and is generally unable to reject the possibility that all preseparation seniority premiums are transferred. ${ }^{13}$ Similarly, Ruhm actually finds larger seniority differentials in postdisplacement than predisplacement jobs for males with less than 20 years' prior tenure. ${ }^{14}$ In contrast, tenure premiums are cut in half for the over-20-years group, suggesting that displacement is quite harmful for these senior workers. ${ }^{15}$ 


\section{POSTDISPLACEMENT JOBLESSNESS}

Although relative wages typically fall following displacement, the dispersion of experiences is extremely large - approximately $40 \%$ of dislocated individuals increase their earnings. ${ }^{16}$ By contrast, almost all laid-off workers are jobless prior to obtaining new employment and, for the vast majority, the period is quite lengthy. For example, analysis of the Displaced Worker Surveys reveals that the median individual was out of work for 24.1 weeks prior to the 1984 survey, and for 18.3 weeks preceding the 1986 survey in the one to four years following displacement, with the duration of unemployment declining as economic conditions improve. ${ }^{17}$ These results understate postlayoff joblessness because they include persons displaced shortly before the survey, whose unemployment spells have often not concluded by the survey date. Ruhm provides information on five-year employment histories for workers experiencing permanent layoffs in the early and middle seventies. ${ }^{18}$ He finds that displaced individuals average more than seven months of unemployment during the five-year period. Excluding the relatively small fraction $(15 \%)$ who avoid unemployment altogether, the expected duration exceeds nine months. Adding in the time out of the labor force, total joblessness surpasses one year.

Evidence that displacement is associated with significantly elevated joblessness does not imply special problems for persons leaving high-seniority jobs. It is commonly assumed that time out of work increases with prior tenure, but, again, the recent empirical evidence is far from compelling. The standard argument is (1) preseparation wages rise with seniority as firm-specific attachments are acquired, (2) reservation wages are an increasing function of previous earnings, (3) since seniority premiums will not be replicated on the new job, the difference between wage offers and reservation wages increases with seniority, (4) as a result, high-tenure workers remain unemployed longer - until their reservation wages fall to the point that they find an acceptable wage offer.

This line of reasoning is questionable in several respects. As discussed above, it is unclear whether the seniority differentials observed in cross-sectional data result from firm-specific or generally applicable attributes and, therefore it is not obvious that long-tenure workers will be unable in replicate prior earnings in new employment. (The previous section indicates that, at least to some extent, they can.) Second, the relationship between predisplacement seniority and reservation wages is essentially unknown. Although reservation wages are positively correlated with prior earnings ceteris paribus, long-tenure workers probably have more family responsibilities, greater attachment to the labor force, and higher aversion to unemployment than their counterparts with less stable employment histories. Each of these factors mitigates against lengthy unemployment.

Recent research suggests that the relationship between prior seniority and postdisplacement joblessness is quite weak. Addison and Portugal, Kletzer, and Podgursky and Swaim all find that tenure is associated with very small increases in male joblessness. ${ }^{19}$ For example, Addison and Portugal estimate that four additional years on the predisplacement job is associated with one extra day out of work. Other individual and economywide effects have much larger impacts, however. For instance, the racial (black/white) differential observed by Podgursky and Swaim is 30 times as large as that from an extra year of tenure. ${ }^{21}$ 
The relationship between employment duration and subsequent joblessness is also highly nonlinear and definition-dependent. Ruhm finds that persons displaced from jobs lasting more than a year are unemployed three to six weeks longer than are those with shorter employment durations, but that there is no additional increase when additional seniority (beyond one year) is obtained. ${ }^{20}$ Furthermore, when time out of work is added in, total joblessness is actually longer for persons with less than a year's seniority than it is for those with greater tenure."

\section{FRINGE BENEFITS}

Because data on fringe benefits is so difficult to obtain, there has been scant examination of whether displacement leads to unusually large reductions of fringe benefits for long-tenure job leavers. One area of special concern is the loss of pension benefits among high-seniority workers who are covered by defined benefit pension plans. ${ }^{22}$ Retirement benefits in such schemes typically depend upon some combination of age, years of service, and highest earnings. Involuntary separations involving long-tenure workers may therefore cause large losses as accumulated years of service and (possibly) earnings are reduced. Ironically, because the actuarial accruals in most plans reach a maximum well before normal retirement ages, highseniority workers displaced in their early to middle fifties are likely to suffer greater pension losses than they would if terminations occurred at later ages. ${ }^{23}$

A second fringe benefit potentially affected by economic dislocation is health insurance. Interestingly, Horvath finds little evidence of lost benefits for dislocated workers who obtain reemployment but much lower rates of group coverage for unemployed workers and persons exiting the labor force. ${ }^{24}$ Losses of health insurance thus appear to be most problematic during periods of postdisplacement joblessness and any effect of prior seniority is likely to be far overshadowed by differences in labor force status.

\section{POLICY IMPLICATIONS}

The results suggest that current displaced-worker assistance policies are seriously misdirected. Although existing programs are rarely explicitly directed toward long-service workers, concern over such individuals is implicit in many cases. For example, it is frequently argued that agricultural and durable goods manufacturing industries need protection in the form of quotas, tariffs, and voluntary restraint agreements because they employ a high proportion of long-tenure workers for whom trade displacement is thought to be especially costly. The same groups most commonly have been eligible for TAA benefits and almost every argument for increasing assistance to displaced workers emphasizes the plight of persons leaving jobs of substantial duration.

Programs narrowly focused on the most senior workers probably are justified. Fhe targeting, however, should be explicit and long tenure should be narrowly defined to include only those with 15 or more years on the preseparation job. Furthermore, lacking evidence that extended unemployment is a special problem for this group, programmatic support should be directed toward facilitating successful reemployment rather than providing extended unemployment benefits (beyond those available to other workers).

Efforts to offset the large earnings losses of long-tenure job leavers may be called for. More generally, recent evidence indicates that postlayoff wage reductions are lasting while increased 
unemployment is largely transitory. This suggests that greater attention should be paid to the type of postdisplacement employment obtained, rather than considering the adjustment process to be completed (and successful) once unemployment ends. For example, workers with more than 20 years' tenure find new jobs relatively quickly but quite probably do so because they accept inferior positions to avoid an extended spell of joblessness. Unfortunately, current policy efforts tend to focus on the initial unemployment, rather than the much longer lasting wage losses.

Involuntary job leavers average almost six months of unemployment in the two years following displacement and, as a result, frequently exhaust unemployment benefits. The provision of extended benefits to trade displaced workers may therefore be a "second best" measure designed to increase the duration of assistance available to at least a fraction of workers whose jobs permanently disappear. A better policy, however, would provide for broader-based supplemental assistance available to all permanently displaced individuals with prolonged joblessness.

Ideally, the current UI and TAA systems should be redesigned to reduce existing adverse incentives while increasing benefits available to the most needy. One possibility would involve increasing the waiting period for payment of first benefits, raising the maximum number of weeks over which assistance could be received, and gradually reducing the size of the weekly benefit. This would simultaneously lower program costs by decreasing payments to the large number of workers with fairly short unemployment spells, increase assistance available to the longest-term unemployed, and improve incentives to search for new employment by raising the marginal cost of unemployment as benefits decline over time.

Five of every six workers experience some joblessness following displacement. In addition to any earnings losses, the majority face a temporary lapse of health insurance benefits. This argues for government or employer provision of transitional group health coverage during the initial unemployment and possibly continuing for a limited period after reemployment. To reduce adverse incentives, the health insurance could be limited in scope (i.e., major medical only) and require contributions by the displaced worker on a means-tested basis. Even with such copayments, the program would be beneficial because of the savings in premium costs associated with group health plans.

Increased economic dislocation has also made it more likely that workers will depart from jobs at which they have considerable accrued pension benefits. ${ }^{25}$ This suggests the need for increased portability of pension benefits. Although the ongoing shift from defined benefit to defined contribution plans will raise portability over time, the majority of currently covered workers are in defined benefit plans where portability is an important concern.

Evidence of special problems for high-tenure workers is quite weak and probably limited to those with extremely long seniority (i.e., over 20 years). There are a number of other groups, however, for whom permanent job loss is especially harmful. Nonwhites and females have longer periods of postdisplacement joblessness and greater earnings reductions than do whites and males. Although it is probably undesirable to target programs exclusively toward women or minorities, policy efforts should take into account the special needs of these groups. Adjustment problems also appear to be more severe for workers displaced by plant closings than by partial 
layoffs and for those losing jobs in depressed regions or during recessions. Explicit targeting of assistance based upon these criteria may therefore be justified. Unfortunately, recent policy changes have reduced the support available to persons losing jobs in depressed local labor markets or during downturns. ${ }^{26}$

Despite the clear mandate for programs that assist displaced workers, our current understanding of the economic consequences of involuntary job loss is inadequate. One reason for this relative ignorance has been an excessive willingness to accept the "conventional wisdom" without testing its accuracy. For example, the BLS restricts their definition of displacement to persons losing jobs of more than three years' duration. This exclusion criteria is justified only if adjustment problems increase with tenure and three years represents a meaningful cutoff point. The evidence presented here suggests potential inaccuracies in both assumptions and argues for the use of broader definitions of displacement. The exclusion of short-tenure individuals is particularly unfortunate given evidence that persons leaving jobs of more than three years' duration face the prospect of repeated turnover and associated prolonged unemployment if the economy slackens following the initial separation. Because they have left lengthy jobs in the recent past, these workers have short current tenure and so are excluded from the BLS definition of displaced individuals.

\section{NOTES}

1. Cycle-adjusted displacement rates have increased $20-40 \%$ between the early seventies and early eighties Daniel S. Hamermesh, "What Do We Know About Worker Displacement in the U.S.," Industrial Relations 28(1989): 51-59.

2. Nearly half of the persons displaced from jobs of three or more years' duration between 1979 and 1985 left manufacturing employment, an industry group that employs less than one-fifth of the labor force. Paul O. Flaim and Ellen Sehgal, "Displaced Workers of 1979-83: How Well Have They Fared," Monthly Labor Review 108 (1985): 3-16; Francis W. Horvath "The Pulse of Economic Change: Displaced Workers of 1981-5," Monthly Labor Review 110 (1987): 3-12.

3. Flaim and Sehgal, "Displaced Workers of 1979-83."

4. Even in the absence of written policies, $36 \%$ of nonunion employers and $59 \%$ of union firms always release more junior workers first (Richard B. Freeman and James L. Medoff, What Do Unions Do [New York: Basic Books, 1984]).

5. Annual layoff rates for household heads with less than a year on the job were more than 13 times as high in the early seventies as it was for their counterparts with more than 20 years' seniority. Christopher J. Ruhm, "The Economic Consequences of Labor Mobility," Industrial and Labor Relations Review 41 (1)(1987): 30-42. Average tenure of workers displaced in the early eighties was less than five years. Douglas L. Kruse "International Trade and the Labor Market Experience of Displaced Workers," Industrial and Labor Relations Review 41 (1988): 402-417.

6. Robert E. Hall "The Importance of Lifetime Jobs in the U.S. Economy," American Economic Review 72 (1982): 716-724; Christopher J. Ruhm, "Career Jobs, Bridge Employment, and Retirement," in Peter B. Doeringer, ed., Bridges to Retirement: The Changing Labor Market for Older Workers (Ithaca, NY: ILR Press, Cornell University, forthcoming). Although Ruhm finds somewhat shorter durations for women, almost $60 \%$ will hold a single job for 10 or more years, and almost half for more than 15 years.

7. These include human capital theory, matching models, agency theories, and testing models. For examples, see Gary S. Becker, Human Capital, 2nd ed. (New York: Columbia University Press, 
1975); Kenneth Burdett, "A Theory of Employee Job Search and Quit Rates," American Economic Review, 68 (1) (1978): 212-220; J. Luis Guasch and Andrew Weiss, "An Equilibrium Analysis of Wage-Productivity Gaps," Review of Economic Studies 49 (1982): 485-498; Edward P. Lazear, "Agency Earnings Profiles, Productivity, and Hours Restrictions," American Economics Review 71(1981): 606-620.

8. For example, much attention is now paid to selection biases that occur when postdisplacement reemployment occurs in a nonrandom manner.

9. Katharine G. Abraham and Henry S. Farber "Job Duration, Seniority, and Earnings" American Economic Review 77, no. 3 (1987): 278-297; Joseph G. Altonji and Robert A. Shokotko, "Do Wages Rise With Job Seniority?" Review of Economic Studies 54 (1987): 437-459.

10. For criticisms of this research, see Kevin Lang, "Reinterpreting the Returns to Seniority," (mimeo, Boston University, 1987); Robert Topel, "Wages Rise With Job Seniority," (mimeo, University of Chicago, 1987).

11. Ruhm, "The Economic Consequences of Labor Mobility."

12. Michael Podgursky and Paul Swaim, "Job Displacement and Earnings Loss: Evidence From the Displaced Worker Survey" Industrial and Labor Relations Review 41, no. 1(1987): 17-29. One recent study, Daniel S. Hamermesh, "The Costs of Worker Displacement," Quarterly Journal of Economics, 52 (1987): 51-75, does show tenure as an important predictor of postdisplacement wage losses. This conclusion, however, depends critically on the assumptions that firm- specific skills provide the only source of tenure premiums and that seniority coefficients obtained from cross-sectional earnings regressions accurately indicate the returns to tenure. Neither assumption appears valid, and so Hamermesh's estimates of displacement losses are questionable.

13. Lori G. Kletzer, "Employment and Earnings Outcomes of Permanent Job Loss: Results from January 1984" (mimeo, Williams College, 1986).

14. Christopher J. Ruhm "Do Earnings lncrease With Job Seniority,"Review of Economics and Statistics (forthcoming).

15. Although average postdisplacement wage reductions appear to be almost unrelated to job duration, the association may be stronger for some industries, occupations, and demographic groups. Ruhm, "Do Earnings Increase With Job Seniority," suggests that the relative costs of losing longduration jobs are greatest for persons employed in managerial, professional, or technical occupations, but Kletzer, "Employment and Earnings Outcomes of Permanent Job Loss," shows the largest reductions for blue-collar workers. These contradictory results indicate the need for further research.

16. See Ruhm, "The Economic Consequences of Labor Mobility," or Podgursky and Swaim, "Job Displacement and Earnings Loss," for evidence.

17. Flaim and Sehgal, "Displaced Workers of 1979-83"; Horvath, "The Pulse of Economic Change."

18. Christopher J. Ruhm, "The Extent and Persistence of Unemployment Following Permanent Quits and Layoffs" (mimeo, Boston University, 1987).

19. John T. Addison and Pedro Portugal, "The Effect of Advance Notification of Plant Closings on Unemployment" Industrial and Labor Relations Review 41(1987): 3-16; Michael Podgursky and Paul Swaim "Duration of Joblessness Following Job Displacement," Industrial Relations 26(1987): 213-226; Kletzer, "Employment and Earnings Outcomes of Permanent Job Loss," finds somewhat larger effects for women.

20. Ruhm, "The Extent and Persistence of Unemployment." 
21. There is some evidence of more adverse impacts on future employment stability for high-tenure jobs losers, especially if a recession shortly follows the initial loss of job (see Christopher J. Ruhm "Job Tenure and Cyclical Changes in Labor Market Dynamics," Review of Economics and Statistics 59, no. 2 (1987): 372-378).

22. See Laurence J. Kotlikoff and David Wise, The Wage Carrot and the Pension Stick: Retirement Benefits and Labor Force Participation. (Kalamazoo, MI: W. E. Upjohn lnstitute for Employment Research, 1989) for a detailed discussion of the structure and incentive effects of private pensions.

23. In defined contribution plans, the employee "owns" the entire accrued pension contribution after a short vesting period. Regardless of seniority, postdisplacement pension losses are thus likely to be quite small. Short-tenure workers who change jobs prior to vesting will be the biggest losers.

24. Horvath, "The Pulse of Economic Change."

25. Close to $50 \%$ of household heads leave career jobs prior to age 60 , and the majority of these terminations appear to be involuntary. Ruhm, "Career Jobs, Bridge Employment, and Retirement."

26. In particular, the state unemployment rates that "trigger" extended UI benefits were raised in 1982 and the national trigger rate was eliminated altogether. The effects of these changes on insured unemployment are discussed by Gary Burtless, "Why is the Insured Unemployment Rate So Low?" Brookings Papers on Economic Activity 1(1983): 225-249. 